\title{
A survey on knowledge and attitudes towards molar-incisor hypomineralization among undergraduate and postgraduate students at the School of Stomatology, Wuhan University
}

Yanchen Liu ${ }^{1,2}$ and Miao He $\mathrm{e}^{1,2^{*}}$

\begin{abstract}
Background: Molar incisor hypomineralization $(\mathrm{MIH})$ is a developmental dental disease, and its clinical management challenges dentists. This study aimed to investigate the knowledge about $\mathrm{MIH}$ and the attitudes towards learning more about $\mathrm{MIH}$ among undergraduate and postgraduate students attending the School of Stomatology, Wuhan University.
\end{abstract}

Methods: This survey was based on a questionnaire modified based on previous studies. The questionnaire was sent to 540 undergraduate and postgraduate students from the School of Stomatology, Wuhan University. The questions covered their clinical experience, perceptions, clinical management, and preferences for further training. Data were analysed with the Chi-square test.

Results: We collected 368 questionnaires (response rate: 68\%). Among them, 89\% (328/368) were eligible for analysis. Most respondents (80\%) had heard of $\mathrm{MIH}$, primarily from classroom teaching. However, only $40 \%$ of the students had observed the disease clinically, and a relatively low proportion of students were familiar with the aetiology, prevalence, differential diagnosis, and treatment of $\mathrm{MIH}$. Most respondents were highly enthusiastic and had great expectations about further systematic teaching about $\mathrm{MIH}$.

Conclusion: Most students in this study had heard of $\mathrm{MIH}$, but few were familiar with the principles of its differential diagnosis. Systematic teaching about MIH is warranted.

Keywords: Clinical management, Dental developmental disease, Molar-incisor hypomineralization

*Correspondence: hemiao@whu.edu.cn

${ }^{1}$ The State Key Laboratory Breeding Base of Basic Science of Stomatology (Hubei-MOST) \& Key Laboratory of Oral Biomedicine Ministry

of Education, School and Hospital of Stomatology, Wuhan University, 237 Luoyu Road, Wuhan 430079, China

Full list of author information is available at the end of the article

\begin{abstract}
Background
Molar-incisor mineralization $(\mathrm{MIH})$ is a disease that causes hypomineralization of tooth enamel. It was first proposed by Weerheijm in 2001 [1], and it was officially defined as an independent disease by the European Academy of Paediatric Dentistry in 2003 [2]. The aetiology of $\mathrm{MIH}$ is currently believed to be related to genetic factors, environmental factors, drug factors, and general
\end{abstract}


conditions that occur in utero and during the first three years after birth [3].

The global average prevalence of MIH is $14.2 \%$ [4], but it varies from country to country. The prevalence of $\mathrm{MIH}$ in children 6-12 years old in China ranges from 4.45 to $25.5 \%[5,6]$. The clinical manifestations of teeth mildly affected by MIH include clearly defined white and lightyellow opacities. In severe cases, the enamel may break down after eruption. There is no unified opinion on treatments for $\mathrm{MIH}$, and currently, the treatments mainly aim to relieve symptoms. Previous studies have found that the oral health-related quality of life of children with MIH is lower than that of children without MIH [7]. The main reasons for the reduced quality of life include tooth sensitivity, which causes chewing discomfort, and coloured opacities on the front teeth, which causes aesthetic problems [8].

For dentists, it is important to distinguish MIH from other dental developmental defects. MIH has gradually received more attention over the years, and several surveys have been conducted on dentist awareness of $\mathrm{MIH}$ [9-11]. Dentists believe that MIH management presents quite a challenge. To date, only two surveys on student awareness have been conducted: one in Germany and one in Saudi Arabia [12, 13]. Given the high prevalence of MIH in China and the lack of awareness among dental students, the present study aimed to investigate the knowledge of MIH and the attitudes towards learning more about MIH among undergraduate and postgraduate students in the School of Stomatology, Wuhan University. We also evaluated whether knowledge of MIH was different among students at different academic levels. The results of this study might influence future curriculum planning.

\section{Methods}

\section{Study design and procedures}

This survey included undergraduates (fourth- and fifthyear undergraduates) and postgraduates (first-, second-, and third-year postgraduates) enrolled in the School of Stomatology, Wuhan University, in January 2021. All current students were included in the sample. Prior to participant enrolment, this study was approved by the Medical Ethics Committee of the School of Stomatology, Wuhan University (\#HGGC-076).

Before the questionnaire was delivered, we conducted a presurvey to ensure that the questions were readily understood. For this study, the questionnaire was provided in electronic form and distributed in public discussion groups (WeChat and QQ software platforms, Tencent Corporate, Shenzhen, China) with assistance from Wenjuanxing (Questionnaire Collection Software, Ranxing Technology Corporate, Changsha, China). All questionnaires were completed voluntarily and anonymously. One week after the questionnaire was distributed, all of the participating groups were notified again as a reminder.

\section{Survey instrument}

The questionnaire had three parts. The first part contained basic information, including each participant's academic level. The second part included disease awareness; the source of knowledge acquisition; the degree of mastery over $\mathrm{MIH}$ aetiology, epidemiology, clinical manifestations, and differential diagnosis; the probability of clinical encounters; and the choice of treatment methods. The third part included the following three questions: Do you want to gain relevant knowledge about MIH? What would you most like to know? What are the principal ways to obtain professional dental knowledge? Between the first and second parts of the questionnaire, a brief introduction to MIH was provided to clarify the subject of the questionnaire and to avoid errors in understanding. The related pictures of MIH used in the questionnaire were from the treatment manual published by Ghanim et al. [14].

To avoid blank items in the questionnaire, the questionnaire was set to skip nonapplicable questions automatically. For example, when a respondent had not been involved in treating $\mathrm{MIH}$, they were not asked about the preferred materials commonly used in clinical practice for treating MIH.

\section{Statistical analyses}

We performed all statistical analyses with SPSS Ver. 26.0 (IBM, NY, USA). The descriptive statistical analyses are presented in distribution tables and frequency tables. The distributions were compared with the chi-square test. The reliability and validity of the questionnaire were verified with the Cronbach's $\alpha$ index and Kaiser-MeyerOlkin (KMO) value, respectively. The threshold for a significant difference was set to 0.05 .

\section{Results}

We collected 368 questionnaires from students at five different academic levels. The response rate of the questionnaire was $68 \%$ (Table 1), and the effective rate of the questionnaire was $89 \%$. The reliability of the questionnaire was 0.852 (Cronbach's $\alpha$ index), and the validity of the questionnaire was 0.889 (KMO test).

Most students had heard of MIH (Table 2), and we found no significant difference between undergraduate and postgraduate students in this aspect $(\mathrm{p}>0.05)$. Moreover, most students had heard about MIH in more than one context. As shown in Table 3, the most common source was classroom teaching, followed by clinical 
Table 1 Recovery and valid questionnaires

\begin{tabular}{llllll}
\hline & Recovery & Valid & Target number & RR (\%) & ER (\%) \\
\hline G1 & 68 & 59 & 79 & 86 & 87 \\
G2 & 69 & 64 & 79 & 87 & 93 \\
G3 & 53 & 53 & 103 & 51 & 100 \\
G4 & 90 & 82 & 135 & 67 & 91 \\
G5 & 88 & 70 & 144 & 61 & 80 \\
Total & 368 & 328 & 540 & 68 & 89 \\
\hline
\end{tabular}

G1 4th-year undergraduate, G2 5th-year undergraduate, G3 1st-year postgraduate

G4 2nd-year postgraduate, G5 3rd-year postgraduate

$R R$ recovery rate, $E R$ effective rate

practice, lectures, journal articles, and other sources. Some students (39\%) had observed MIH clinically. The proportions of students who had observed MIH clinically were significantly different among the different academic levels $(\mathrm{p}<0.05)$. However, only 66 students $(25 \%)$ were confident in identifying $\mathrm{MIH}$, and the professed ability to identify MIH was significantly different among the different academic levels $(p<0.05)$. Few students knew the diagnostic principles of $\mathrm{MIH}$. The proportions of students who knew the diagnostic principles of MIH were significantly different between academic levels $(\mathrm{p}<0.05)$. All of the aetiologies of MIH (i.e., genetic factors, pregnancy and postnatal factors, drug factors, environment factors) were known by only 93 students (35\%). Most students believed that the prevalence of MIH was less than $15 \%$.

Only 3\% of respondents had performed an MIH treatment (Table 3). Among these students, most were more inclined to use a pit and fissure seal, instead of a fluoride varnish, for teeth mildly damaged by MIH. However, for teeth affected by MIH with moderate to severe dentin sensitivity but no pulp symptoms, no treatment was favoured significantly over the other choices.

Among the respondents who had observed MIH clinically, most (63\%) were confident in distinguishing $\mathrm{MIH}$ from dental fluorosis, dentin hypoplasia, and other developmental dental diseases (Table 4). The rate of observing MIH clinically was $13 \%$. The probability that students would encounter $\mathrm{MIH}$ clinically at frequencies of once per week, once per month, once per 6 months, once per year, and once per $>1$ year were $13 \%, 34 \%, 38 \%, 7 \%$, and $10 \%$, respectively.

The vast majority of students (90\%) thought it was necessary to add MIH to the curriculum for future systematic teaching (Table 2). They felt that the most desirable aspects to learn were the clinical manifestations, differential diagnosis, and treatment methods. The most important ways to learn this knowledge were thought to be from textbooks, the literature, the internet, and lectures.

\section{Discussion}

There are obvious differences in the MIH prevalence among previously published studies, possibly due to differences in the populations, research methods, diagnostic criteria, etc. Compared to unaffected children, children with MIH had higher risks of caries and required more dental treatments [15]. Severe MIH can affect both the quality of life and oral function in children [16]. Without intervention, after two years, molars affected by mild MIH progress to moderate or severe MIH, with enamel breakdown [17]. If we do not initiate preventive measures, the cost of treating MIH will become a heavy

Table 2 Source of MIH knowledge and oral professional knowledge

\begin{tabular}{|c|c|c|c|c|c|c|}
\hline Total & G1 & G2 & G3 & G4 & G5 & Total \\
\hline \multicolumn{7}{|c|}{ Have you heard of MIH? (YES) } \\
\hline \multicolumn{7}{|c|}{ Do you want to learn MIH more systematically? (YES) } \\
\hline \multicolumn{7}{|c|}{ Which part do you want to study in MIH?* } \\
\hline Clinical manifestation & $46(58 \%)$ & $47(59 \%)$ & $50(49 \%)$ & $72(53 \%)$ & $63(44 \%)$ & $278(85 \%)$ \\
\hline Differential diagnosis & $43(54 \%)$ & $50(63 \%)$ & $48(47 \%)$ & $73(54 \%)$ & $61(42 \%)$ & $275(84 \%)$ \\
\hline Treatment methods & $43(54 \%)$ & $50(63 \%)$ & $50(49 \%)$ & $78(58 \%)$ & $63(44 \%)$ & $284(87 \%)$ \\
\hline Aetiology & $32(41 \%)$ & $38(48 \%)$ & $40(39 \%)$ & $68(50 \%)$ & $50(35 \%)$ & $228(70 \%)$ \\
\hline Epidemiology & $22(28 \%)$ & $26(33 \%)$ & $30(29 \%)$ & $52(39 \%)$ & $37(26 \%)$ & $167(51 \%)$ \\
\hline \multicolumn{7}{|c|}{ Where do you usually learn oral knowledge?* } \\
\hline Textbook & $59(75 \%)$ & $52(66 \%)$ & $40(39 \%)$ & $59(44 \%)$ & $58(40 \%)$ & $268(82 \%)$ \\
\hline Journals & $25(32 \%)$ & $33(42 \%)$ & $35(34 \%)$ & $62(46 \%)$ & $57(40 \%)$ & $212(65 \%)$ \\
\hline Internet & $30(38 \%)$ & $37(47 \%)$ & $35(34 \%)$ & $63(47 \%)$ & $47(33 \%)$ & $212(65 \%)$ \\
\hline Lectures & $9(11 \%)$ & $21(27 \%)$ & $29(28 \%)$ & $60(44 \%)$ & $50(35 \%)$ & $169(52 \%)$ \\
\hline
\end{tabular}

G1 4th-year undergraduate, G2 5th-year undergraduate, G3 1st-year postgraduate, G4 2nd-year postgraduate, G5 3rd-year postgraduate

*These questions are multiple choice 
Table 3 Students' responses about the aetiology, diagnosis and prevalence of $\mathrm{MIH}$

\begin{tabular}{|c|c|c|c|c|c|c|}
\hline Total & 47 & 47 & 47 & 69 & 54 & 264 \\
\hline \multicolumn{7}{|l|}{ Where did you learn about MIH?** } \\
\hline Journals & $2(4 \%)$ & $7(15 \%)$ & $5(11 \%)$ & $10(14 \%)$ & $13(24 \%)$ & $37(14 \%)$ \\
\hline Lectures & $2(4 \%)$ & $5(11 \%)$ & $7(15 \%)$ & $21(30 \%)$ & $21(39 \%)$ & $56(21 \%)$ \\
\hline Classroom teaching & $43(91 \%)$ & $38(81 \%)$ & $27(57 \%)$ & $48(70 \%)$ & $32(59 \%)$ & $188(71 \%)$ \\
\hline Clinical practice & $3(6 \%)$ & $15(32 \%)$ & $25(53 \%)$ & $45(65 \%)$ & $23(43 \%)$ & $111(42 \%)$ \\
\hline Have you met MIH in clinical? (YES) & 0 & $10(21 \%)$ & $26(55 \%)$ & $40(58 \%)$ & $28(52 \%)$ & $104(39 \%)$ \\
\hline \multicolumn{7}{|l|}{ What do you think is the aetiology of MIH?* } \\
\hline Genetic factors & $41(87 \%)$ & $41(87 \%)$ & $35(74 \%)$ & $56(81 \%)$ & $40(74 \%)$ & $213(81 \%)$ \\
\hline Pregnant and postnatal factors & $41(87 \%)$ & $38(81 \%)$ & $40(85 \%)$ & $56(81 \%)$ & $42(78 \%)$ & $179(68 \%)$ \\
\hline Drug factors & $29(62 \%)$ & $31(66 \%)$ & $19(40 \%)$ & $30(43 \%)$ & $31(57 \%)$ & $140(53 \%)$ \\
\hline Environment factors & $28(60 \%)$ & $39(83 \%)$ & $24(51 \%)$ & $32(46 \%)$ & $38(70 \%)$ & $161(61 \%)$ \\
\hline All of above & $22(47 \%)$ & $24(51 \%)$ & $11(23 \%)$ & $17(25 \%)$ & $19(35 \%)$ & $93(35 \%)$ \\
\hline Do you know the principles of diagnosis of MIH? (YES) & $1(2 \%)$ & $3(6 \%)$ & $7(15 \%)$ & $22(32 \%)$ & $10(19 \%)$ & $43(16 \%)$ \\
\hline \multicolumn{7}{|l|}{ What do you think the prevalence of MIH? } \\
\hline $0-15 \%$ & $28(60 \%)$ & $23(49 \%)$ & $25(53 \%)$ & $41(59 \%)$ & $39(72 \%)$ & $156(59 \%)$ \\
\hline $15-30 \%$ & $18(38 \%)$ & $22(47 \%)$ & $18(38 \%)$ & $27(39 \%)$ & $15(28 \%)$ & $100(38 \%)$ \\
\hline $30-60 \%$ & $1(2 \%)$ & $2(4 \%)$ & $4(9 \%)$ & $1(1 \%)$ & 0 & $8(3 \%)$ \\
\hline More than $60 \%$ & 0 & 0 & 0 & 0 & 0 & $0(0 \%)$ \\
\hline Have you did a treatment of MIH? (Yes) & 0 & 0 & 0 & $5(7 \%)$ & $4(7 \%)$ & $9(3 \%)$ \\
\hline $\begin{array}{l}\text { Which treatment would you provide for this is a newly erupted first molar with plaque on } \\
\text { buccal surface? }\end{array}$ & & & & & & $9(3 \%)$ \\
\hline Fluoride varnish & 0 & 0 & 0 & $3(4 \%)$ & $4(7 \%)$ & $7(3 \%)$ \\
\hline Pit and fissure sealant & 0 & 0 & 0 & $2(3 \%)$ & 0 & $2(1 \%)$ \\
\hline Observation & 0 & 0 & 0 & 0 & 0 & 0 \\
\hline $\begin{array}{l}\text { Which treatment would you perfer to do for this newly erupted first permanent molar with } \\
\text { post-eruptive breakdown?The tooth is sensitive to air and the patient is cooperative }\end{array}$ & & & & & & $9(3 \%)$ \\
\hline Fluoride varnish & 0 & 0 & 0 & $1(1 \%)$ & $1(2 \%)$ & $2(1 \%)$ \\
\hline Glass ionomer & 0 & 0 & 0 & $1(1 \%)$ & $1(2 \%)$ & $2(1 \%)$ \\
\hline Composite resin & 0 & 0 & 0 & $1(1 \%)$ & 0 & $1(0 \%)$ \\
\hline Occlusal veneer & 0 & 0 & 0 & $2(3 \%)$ & 0 & $2(1 \%)$ \\
\hline Preformed crowns & 0 & 0 & 0 & 0 & $2(4 \%)$ & $2(1 \%)$ \\
\hline Extract & 0 & 0 & 0 & 0 & 0 & 0 \\
\hline
\end{tabular}

G1 4th-year undergraduate, G2 5th-year undergraduate, G3 1st-year postgraduate, G4 2nd-year postgraduate, G5 3rd-year postgraduate

*These questions are multiple choice

Table 4 Clinical experience of $\mathrm{MIH}$

\begin{tabular}{|c|c|c|c|c|c|c|}
\hline Total & 0 & 10 & 26 & 40 & 28 & 104 \\
\hline \multicolumn{7}{|l|}{ How often do you meet MIH in clinical? } \\
\hline Once a week & 0 & 0 & $3(12 \%)$ & $8(20 \%)$ & $2(7 \%)$ & $13(8 \%)$ \\
\hline Once a month & 0 & $4(40 \%)$ & $11(42 \%)$ & $11(28 \%)$ & $9(32 \%)$ & $35(21 \%)$ \\
\hline Once half a year & 0 & $3(30 \%)$ & $8(31 \%)$ & $17(43 \%)$ & $11(39 \%)$ & $39(23 \%)$ \\
\hline Once a year & 0 & $1(10 \%)$ & $2(8 \%)$ & $1(3 \%)$ & $3(11 \%)$ & $7(4 \%)$ \\
\hline Once more than a year & 0 & $2(20 \%)$ & $2(8 \%)$ & $3(8 \%)$ & $3(11 \%)$ & $10(6 \%)$ \\
\hline $\begin{array}{l}\text { Can you distinguish MIH with other dental } \\
\text { development disease? (Yes) }\end{array}$ & 0 & $3(30 \%)$ & $14(54 \%)$ & $30(75 \%)$ & $19(68 \%)$ & $66(63 \%)$ \\
\hline
\end{tabular}

G1 4th-year undergraduate G2 5th-year undergraduate G3 1st-year postgraduate G4 2nd-year postgraduate G5 3rd-year postgraduate 
burden on the country and the individuals [18]. Therefore, it is important to study the aetiology, treatment, and awareness of MIH.

Judging from the current data, the situation is not optimistic. Although $80 \%$ of students had heard of $\mathrm{MIH}$, only $20 \%$ of the respondents thought they could accurately evaluate it. Student enthusiasm for learning MIHrelated knowledge was very high, which showed that we need to increase the teaching of MIH-related theoretical knowledge.

For the question of "How often do you encounter MIH clinically?", the results showed a far lower frequency than the frequency experienced by the authors in encountering patients with MIH in clinical settings. This discrepancy might be explained by several reasons. First, the authors work in the paediatric dentistry department; thus, we have come into contact with a large number of patients with MIH. Second, the authors have a better understanding of the theoretical knowledge of MIH. In contrast, the respondents were studying different majors and lacked sufficient opportunities to encounter patients with MIH clinically or to study MIH systematically.

We found no difference among the different academic levels in regards to wishing to learn more about MIH. Most students desired to learn the clinical manifestations, differential diagnosis, and treatment for MIH. This result reflected the urgent clinical need for knowledge about the principles of MIH diagnosis and treatment.

The different academic levels acquired knowledge through different sources. As the respondents aged, they gradually changed their ways of acquiring knowledge, from textbooks to journals, lectures, and then social platforms (e.g., blogs). On the one hand, this trend reflected the convenience of current networks; on the other hand, it also reflected the dentist's growth process, from passive learning to active learning. By searching for reading materials, students can improve their knowledge reserve and build their own experience system.

In this survey, nearly $40 \%$ of interviewees had observed MIH clinically, but only $10 \%$ had experienced treating $\mathrm{MIH}$. At present, there is no global consensus on $\mathrm{MIH}$ treatment methods, and treatment principles often lack clear indicators. In 2017, Steffen et al. proposed an MIH treatment-need index (MIH-TNI) with an MIH treatment-need coefficient, which could assist in establishing an MIH treatment system [19].

Compared with the data in the two published studies thus far, the awareness of Chinese students is lower than that of students in Germany and Saudi Arabia [12, 13]. However, Chinese students' ability to diagnose MIH increases with grades, which may be due to their increase in clinical experience. In addition, we also compared the awareness between students in our study with oral health care practitioners (OHCPs) who have been practising for many years, including general dental practitioners (GDPs) and oral health therapists (OHTs) [10]. As many as $70 \%$ of OHCPs recognise $\mathrm{MIH}$, which is much higher than that of the dental students $[13,20]$. In the future, accordingly, the introduction of MIH in paediatric dentistry courses at the undergraduate and graduate levels is necessary, and surveys should be conducted before and after teaching and learning to evaluate the outcomes.

\section{Conclusion}

The present study showed that students attending the School of Stomatology, Wuhan University had some understanding of $\mathrm{MIH}$, but their knowledge was not comprehensive. They had a weak grasp of the key diagnostic and treatment aspects, and feel a strong need to learn more about MIH. Therefore, based on our research results, we recommend that comprehensive, systematic training on MIH should be required at the undergraduate level, and additional training should be offered at the postgraduate level.

\section{Acknowledgements \\ We sincerely thank all of the dental students for participating in this survey.}

\section{Authors' contributions}

$\mathrm{MH}$ had the initial idea and designed the study. YCL performed the analysis and interpretation of the data and drafted the manuscript. $\mathrm{MH}$ edited the manuscript and gave the final approval. All authors reviewed the manuscript. Both authors read and approved the final manuscript.

\section{Funding}

This work was funded by the National Natural Science Foundation of China (Grant No. 81970904 to M.H.).

\section{Availability of data and materials}

The dataset used and/or analysed during the current study is available from the corresponding author on reasonable request.

\section{Declarations}

\section{Ethics approval and consent to participate}

This study was approved by the Medical Ethics Committee of the School of Stomatology, Wuhan University (\#HGGC-076). Participants consented to participate in writing and submitted the completed questionnaire. This research was conducted in accordance with the World Medical Association Declaration of Helsinki.

Consent for publication

The participants consented in writing to publish the collected data.

Competing interests

The authors declare that they have no competing interests.

\section{Author details}

${ }^{1}$ The State Key Laboratory Breeding Base of Basic Science of Stomatology (Hubei-MOST) \& Key Laboratory of Oral Biomedicine Ministry of Education, School and Hospital of Stomatology, Wuhan University, 237 Luoyu Road, Wuhan 430079, China. ${ }^{2}$ Department of Paediatric Dentistry, School and Hospital of Stomatology, Wuhan University, Wuhan 430079, China. 
Received: 6 October 2021 Accepted: 18 January 2022

Published online: 26 January 2022

\section{References}

1. Weerheijm KL, Jalevik B, Alaluusua S. Molar-incisor hypomineralisation. Caries Res. 2001;35(5):390-1.

2. Weerheijm KL, Duggal M, Mejare I, Papagiannoulis L, Koch G, Martens LC, Hallonsten AL. Judgement criteria for molar incisor hypomineralisation $(\mathrm{MIH})$ in epidemiologic studies: a summary of the European meeting on MIH held in Athens, 2003. Eur J Paediatr Dent. 2003;4:110-3.

3. Santos M, Maia LC. Molar incisor hypomineralization: morphological, aetiological, epidemiological. In: Contemporary approach to dental caries. InTech; 2012, pp. 443-466.

4. Zhao D, Dong B, Yu D, Ren Q, Sun Y. The prevalence of molar incisor hypomineralization: evidence from 70 studies. Int J Paediatr Dent. 2018:28:170-9.

5. Li J, Li L. Investigation of molar-incisor hypomineralization among children from 6 to 11 years in Lucheng District, Wenzhou City. Shanghai J Stomatol. 2012;021:576-9.

6. Sui W, Wu H, Yuan J, Yao H, Hong Y. Current situation and influencing factors of molar-incisor hypomineralization in primary school students in Soozhow China. Chin J Conserv Dent. 2017:027(002):103-7.

7. Barros D, Deus MLDFAD, Figueiredo CP, Silva MM, Martins PS, Castro MC, De L. Impact of molar-incisor hypomineralization on oral health-related quality of life in schoolchildren. 2016;30(1).

8. Ebel M, Bekes K, Klode C, Hirsch C. The severity and degree of hypomineralisation in teeth and its influence on oral hygiene and caries prevalence in children. Int J Paediatr Dent. 2018;28:648-57.

9. Tagelsir A, Dean JA, Eckert GJ, Martinez-Mier EA. U.S. Pediatric Dentists' Perception of Molar Incisor Hypomineralization; 2018.

10. Gambetta-Tessini K, Mariño R, Ghanim A, Calache H, Manton DJ. Knowledge, experience and perceptions regarding molar-incisor hypomineralisation $(\mathrm{MIH})$ amongst Australian and Chilean public oral health care practitioners. BMC Oral Health. 2016;16:75.

11. Hussein AS, Ghanim AM, Abu-Hassan MI, Manton DJ. Knowledge, management and perceived barriers to treatment of molar-incisor hypomin eralisation in general dental practitioners and dental nurses in Malaysia. Eur Archi Paediat Dent. 2014;15(5):301-7.

12. Elhennawy K, Anang M, Splieth C, Bekes K, Schwendicke F. Knowledge, attitudes, and beliefs regarding molar incisor hypomineralization $(\mathrm{MIH})$ amongst German dental students; 2020.

13. Silva MJ, Alhowaish L, Ghanim A, Manton DJ. Knowledge and attitudes regarding molar incisor hypomineralisation amongst Saudi Arabian dental practitioners and dental students. Eur Archi Paediat Dent. 2016;17(4):215-22.

14. Ghanim A, Silva MJ, Elfrink M, Lygidakis NA, Mariño RJ, Weerheijm KL Manton DJ. Molar incisor hypomineralisation (MIH) training manual for clinical field surveys and practice. Eur Archi Paediat Dent. 2017;18(4):1-18.

15. Jälevik B, Klingberg G. Treatment outcomes and dental anxiety in 18-yearolds with $\mathrm{MIH}$, comparisons with healthy controls - a longitudinal study. Int J Paed Dent. 2012;22(2):85-91.

16. Gomez MJR, Mejia LP, Velandia LM, Alvarez LV. Oral health-related quality of life in Colombian children with molar-incisor hypomineralization. AOL. 2018;31(1):38-44.

17. Neves AB, Americano G, Soares DV, Soviero VM. Breakdown of demarcated opacities related to molar-incisor hypomineralization: a longitudinal study. 2018.

18. Schneider PM, Silva M. Endemic molar incisor hypomineralization: a pandemic problem that requires monitoring by the entire health care community. 2018.

19. Steffen R, Krmer N, Bekes K. The Würzburg MIH concept: the MIH treatment need index (MIH TNI). Eur Arch Paediat Dent. 2017;18(Suppl 1):1-7.

20. Kalkani M, Balmer RC, Homer RM, Day PF, Duggal MS. Molar incisor hypomineralisation: experience and perceived challenges among dentists specialising in paediatric dentistry and a group of general dental practitioners in the UK. Eur Arch Paediatr Dent. 2015;17(2):81-8.

\section{Publisher's Note}

Springer Nature remains neutral with regard to jurisdictional claims in published maps and institutional affiliations.
Ready to submit your research? Choose BMC and benefit from:

- fast, convenient online submission

- thorough peer review by experienced researchers in your field

- rapid publication on acceptance

- support for research data, including large and complex data types

- gold Open Access which fosters wider collaboration and increased citations

- maximum visibility for your research: over $100 \mathrm{M}$ website views per year

At BMC, research is always in progress.

Learn more biomedcentral.com/submissions 